\title{
ANÁLISE SOBRE AÇÃO EMPREENDEDORA E POLIITICAS PÚBLICAS NO APL MOVELEIRO DE UBÁ, MG
}

\author{
ANALYSIS ON THE ENTREPRENEURIAL ACTION AND PUBLIC \\ POLICY AT THE FURNITURE CLUSTER OF UBÁ, MG
}

\section{Andréia Aparecida Albino ${ }^{1}$, Afonso Augusto Teixeira de Freitas de Carvalho Lima ${ }^{2}$, Sebastião Décio Coimbra de Souza ${ }^{3}$, Ricardo Roberto Behr ${ }^{4}$ e Ronise Suzuki de Oliveira ${ }^{5}$}

\section{Resumo}

Com base na reconhecida importância dos Arranjos Produtivos Locais para o desenvolvimento socioeconômico das regiões, apresenta-se, neste trabalho, um estudo de caso que envolve a evolução, discussões sobre o papel das ações empreendedoras e a influência das políticas públicas sobre o APL moveleiro de Ubá, Minas Gerais, por meio de levantamento bibliográfico e pesquisa de campo. A pesquisa de campo compreendeu entrevistas com atores estratégicos ligados ao APL. Os resultados preliminares indicaram que as políticas públicas tiveram participação bastante limitada no surgimento e desenvolvimento do APL e que é preciso investigar a diversidade das empresas componentes do APL para fazer proposições de políticas adequadas e direcionadas aos diferentes tipos de empresas que se fazem presentes no arranjo. Concluiu-se também que ação empreendedora exerceu papel determinante no desenvolvimento do polo.

Palavras-chave: Arranjos Produtivos Locais; Desenvolvimento Local; APL Moveleiro de Ubá; Ação Empreendedora; Políticas Públicas.

\footnotetext{
1 Mestranda em Administração da Universidade Federal de Viçosa. E-mail: andreia.albino@ufv.br

2 Doutor em Engenharia de Produção. Professor do Departamento de Administração da Universidade Federal de Viçosa. E-mail: afonsoli@ufv.br

3 Doutor em Engenharia de Produção. Professor do Departamento de Engenharia de Produção da Universidade Estadual Norte Fluminense. E-mail: decio@uenf.br

4 Doutor em Engenharia de Produção. Professor do Departamento de Administração da Universidade Federal do Espírito Santo. E-mail: ricardobehr@hotmail.com

5 Mestranda em Administração da Universidade Federal de Viçosa. E-mail: ronisesuzuki@ufv.br
} 


\begin{abstract}
Based on recognized importance of industrial clusters for the socio-economic development of regions, this work presents a case study involving the evolution, discussions on the role of entrepreneurial activities and the influence of public policies on the development of the furniture cluster of Ubá, Minas Gerais. The methodology adopted included a survey, interviews with strategic actors of the cluster, and analysis comparative data. Preliminary results indicate that public policies had limited involvement in the emergence and development of APL, and indicate the need to investigate the diversity of patterns of business components of local cluster order to propose appropriate policies for each different type of companies. The main conclusion is that the key role in the genesis and development of the furniture cluster of Ubá was the entrepreneurial action of the local businessmen.

Keywords: Industrial Clusters; Local Development; Furniture Cluster of Ubá; Entrepreneurial Action; Public Policy.
\end{abstract}

\title{
1 Introdução
}

Um fenômeno recente, observado na economia de determinadas regiões do Brasil, é que a oferta de emprego e o crescimento industrial, em muitas cidades do interior, têm apresentado índices elevados, enquanto as capitais não apresentam o mesmo vigor. Para Para Grassi (2009), este processo indica que vem ocorrendo uma descentralização industrial no país, fato que remete à importância das aglomerações industriais. Verifica-se, na literatura econômica industrial, que tem crescido estudos sobre a importância dessas aglomerações para o desenvolvimento econômico e aumento da competitividade das empresas (CROCCO; HORÁCIO, 2001).

Para Lastres, Cassiolato e Maciel (2003), o aproveitamento das sinergias coletivas geradas pela participação em aglomerações produtivas locais efetivamente fortalece as chances de sobrevivência e crescimento das empresas e, para que essas se desenvolvam e se sustentem, é necessário um cenário de cooperação e de competitividade bastante intenso.

Brito (2000) explica que essas aglomerações contribuem para o desenvolvimento regional por gerarem benefícios sociais, com base no surgimento de um conjunto de serviços e fornecedores em âmbito local. Outro fator relevante é o fato de uma grande parcela desse aparato ser composto por micro e pequenas empresas que têm sua posição competitiva reforçada ao privilegiarem relacionamentos de cooperação nos APLs.

Dentro desse contexto, o fortalecimento de cadeias produtivas no desenvolvimento dos Arranjos Produtivos Locais (APLs) vem sendo uma das estratégias mais bem-sucedidas para a promoção do desenvolvimento local e regional. Um exemplo que alcançou considerável destaque no cenário nacional é o APL Moveleiro de Ubá, em Minas Gerais, que, recentemente, foi incluído entre os onze APLs selecionados pelo Governo Federal para receber apoio integrado necessário ao seu desenvolvimento (INTERSIND, 2005). Dessa forma, é importante investigar a participação do poder público, das políticas públicas e dos empreendedores locais e avaliar suas contribuições para o surgimento e o desenvolvimento do APL.

Além da introdução, este trabalho está organizado de modo a apresentar o referencial teórico necessário à compreensão do objeto de estudo, seguido da metodologia proposta. Apresenta resultados e discussões acerca do APL moveleiro de Ubá, frente à questão das políticas públicas, apresenta algumas conclusões preliminares seguidas das referências consultadas.

Rev. Adm. UFSM, Santa Maria, v. 3, n. 2, p. 230-244, mai./ago. 2010 


\section{Referencial teórico}

A estrutura do referencial teórico considera a formação de clusters, conceituação e importância dos APLs, apresenta panoramas da indústria moveleira mundial, nacional e local, e discorre sobre a iniciativa privada em parceria com o setor público e privado de outras naturezas para promover cooperação entre os agentes estratégicos do APL.

\subsection{Globalização e os clusters}

Para Diniz (2000), a globalização vem reafirmando e fortalecendo os conceitos de Região e Localidade através da ratificação, ou mesmo aumento, das diferenças entre as regiões. Dessa forma, o mundo é cada vez mais unificado e indissolúvel, pois a tecnologia da comunicação e da informação permite que extremos opostos do globo se comuniquem em tempo real, que dados, documentos e contratos viajem virtualmente sem perda de tempo, que grande parte dos serviços possa ser oferecida à distância.

E são essas mesmas particularidades que, nesse contexto de competição universalizada, tornam-se fatores diferenciais que tendem a ser explorados por empresas, regiões e países:

\footnotetext{
Ao mesmo tempo, o processo de globalização induz a criação de blocos regionais. O processo de unificação européia, a partir da década de 1950, e seus sucessivos avanços e ampliações, ao aumentar o comércio intra-regional e fortalecer o bloco europeu, passou a pressionar outros países e regiões no sentido de se defenderem do protecionismo regional, criando novos blocos econômicos, a exemplo do ASEAN, NAFTA, MERCOSUL, entre outros, demonstrando uma situação paradoxal: globalização e regionalização como duas forças simultâneas e contraditórias, produto do mesmo processo. (DINIZ, 2000, p.3).
}

Surge, então, a percepção de que as diferenças regionais, as capacitações específicas, poderiam ser mais bem aproveitadas e exploradas como diferencial de competitividade.

Nesse contexto, a importância da formação de aglomerações ou clusters se torna bastante nítida, e configurações e terminologias vêm sendo empregadas no sentido de caracterizálos. Os clusters podem ser definidos como concentrações geográficas de companhias e instituições interrelacionadas num setor específico e englobam uma gama de empresas e outras entidades importantes para a competição, incluindo, por exemplo, fornecedores de insumos sofisticados, tais como, componentes, maquinário, serviços e fornecedores de infraestrutura especializada. (PORTER, 1990). No Brasil, o desenvolvimento de clusters é incentivado, entre outros programas, pelas estratégias dos Fóruns de Produtividade do Governo Federal, ancorados em uma dinâmica interativa para trabalhar as cadeias produtivas em escala plena.

A discussão sobre clusters, ou Arranjos Produtivos Locais - APLs, vem adquirindo crescente importância com a mudança do ambiente competitivo das empresas. Tais modificações ocorrem simultaneamente à emergência de um novo paradigma tecnológico que impôs um processo produtivo mais intensivo em conhecimento (CROCCO; HORÁCIO, 2001).

Esforços centrados na metodologia de clusters estimulam as empresas a se tornarem mais envolvidas no processo de desenvolvimento regional. O diálogo entre empresas, governo, universidades e instituições de apoio tende a ocorrer com maior grau de objetividade, tornando as ações mais eficazes. (DINIZ, 1993). 


\subsubsection{Conceituação e importância dos APLs}

A Rede de Sistemas Produtivos e Inovativos do Instituto de Economia da Universidade Federal do Rio de Janeiro (RedeSist) aponta a seguinte definição para APL: Os APLs são aglomerações territoriais de agentes econômicos, políticos e sociais, com foco em um conjunto específico de atividades econômicas e que apresentam vínculos e interdependência, envolvendo a participação de empresas que podem ser produtoras de bens e serviços finais e até fornecedoras de insumos, equipamentos, prestadoras de consultoria e serviços, comercializadoras, clientes, entre outros, e sua variada forma de representação e associação. Incluem também outras instituições públicas e privadas voltadas para formação e capacitação de recursos humanos, pesquisa, desenvolvimento e engenharia, política, promoção e financiamento (REDESIST, 2008). Em uma definição mais sucinta, Brito (2000) define os aglomerados ou arranjos produtivos locais como concentrações geográficas de atividades econômicas similares e/ou fortemente interrelacionadas ou interdependentes.

A lógica do apoio aos APLs parte do pressuposto de que diferentes atores locais (empresários individuais, sindicatos, associações, entidades de capacitação, de educação, de crédito, de tecnologia, agências de desenvolvimento, entre outras) podem mobilizar-se e, de forma coordenada, identificar suas demandas coletivas, por iniciativa própria ou por indução de entidades envolvidas com o segmento.

Nesse sentido, a metodologia de atuação conjunta em APLs busca um acordo entre os atores locais para organizarem suas demandas em um plano de desenvolvimento único e, ao mesmo tempo, comprometê-los com as formas possíveis de solução, em prol do desenvolvimento do APL. (SEBRAE, 2004).

O argumento para a existência de APLs é que, onde houver produção de qualquer bem ou serviço, haverá sempre um arranjo em torno dessa produção que, necessariamente, envolverá atividades relacionadas à aquisição de matérias-primas, máquinas e demais insumos, entre outros. (LASTRES; CASSIOLATO, 2001). Assim, as empresas atuam em torno de uma atividade principal. O APL situa-se em um espaço geográfico que pode pertencer a um município ou conjunto de municípios que possuam alguns sinais de identidade coletiva, como fatores sociais, culturais, econômicos, políticos, ambientais ou históricos (BRITO; ALBAGLI, 2001). Dessa forma, as empresas que compõem um APL mantêm algum vínculo de articulação, interação, cooperação e aprendizagem entre si e com outros agentes locais, como governo, associações empresariais, instituições de crédito e de ensino e pesquisa.

Para Delgado (2005), o desenvolvimento econômico é alcançado com a geração de um produto potencial, com melhoria dos métodos produtivos, da ocupação de recursos ociosos e transferência de renda, de modo que é defendida pelo autor uma forte intervenção de políticas públicas mediante a dotação de bens equalizadores providos pela esfera pública, eficazes na geração do incremento do produto e da produtividade.

De um modo mais amplo, os aglomerados representam uma maneira nova e complementar de dividir e entender a economia, de organizar o pensamento e a prática sobre o desenvolvimento econômico e de definir as políticas públicas (PORTER, 1999, p. 265).

Para Porter (1999), a linha de ação dos governos deve ser na direção da remoção de obstáculos à produtividade e à inovação e alguns papéis do governo que mais interessam ao desenvolvimento empresarial são o de melhorar a capacidade microeconômica geral da economia (por meio do aumento da eficiência e da qualidade dos insumos básicos das empresas: 
mão de obra, infraestrutura física e informações econômicas especializadas, bem como o fomento de instituições que forneçam estes elementos) e definir regras e incentivos microeconômicos gerais que rejam a competição e encorajem o crescimento da produtividade. $\mathrm{O}$ autor ainda sugere que as políticas governamentais bem-sucedidas são aquelas que criam um ambiente em que as empresas são capazes de ganhar vantagem competitiva.

Uma consideração interessante sobre os arranjos produtivos locais é sugerida por Lastres, Cassiolato e Maciel (2003) ao afirmarem que a competitividade das empresas e organizações pode estar relacionada à abrangência das redes em que estão inseridas, assim como a intensidade do uso que fazem das mesmas.

Cassiolato e Lastres (2001) e Pereira e Carvalho (2008) ressaltam ainda que as concentrações geográficas de empresas propiciam condições para que haja o estabelecimento de ações conjuntas entre os atores que se relacionam nessas concentrações e a consequente geração de externalidades positivas sustentáveis.

Segundo Awuah (2001), as relações interfirmas são uma fonte de recursos que podem ser explorados para o desenvolvimento de competências. Tais competências, de acordo com Prahalad e Hammel (1990), são importantes para a criação de vantagens competitivas de caráter sustentável. Schmitz (1995) e Porter (1999) também ressaltaram a importância das ações conjuntas como forma de criar vantagem competitiva, e essas podem ser mais bem percebidas em aglomerações.

\subsection{Panoramas da indústria moveleira}

Segue uma descrição do setor moveleiro em níveis internacional, nacional e local.

\subsubsection{Cenário internacional do setor moveleiro}

A produção mundial de móveis está distribuída, principalmente, entre países desenvolvidos, como Estados Unidos (cerca de 24\% da produção mundial), Itália (10\%) e Alemanha (8\%). Também merecem destaque o Japão (com 6\% da produção mundial), a França (4\%), Reino Unido (4\%) e Canadá (4\%) (ABIMÓVEL, 2005). A indústria moveleira mundial destaca-se também como um setor intensivo em mão de obra e, portanto, importante na geração de empregos. (CROCCO; HORACIO, 2001).

De acordo com o panorama do setor moveleiro de 2005, divulgado pela Associação Brasileira das Indústrias do Mobiliário (ABIMÓVEL) e Rodrigues, (2006), no período de 1995 a 2005, o comércio de móveis expandiu-se em 9\% em nível global, com uma mudança na forma de produção. Hoje as empresas priorizam a produção de móveis em regiões onde os custos de produção são mais reduzidos, o que ocasionou uma migração da produção dos países de primeiro mundo para os de terceiro. Dessa forma, grandes produtores mundiais expandiram sua força de mercado pelas vantagens competitivas no preço e fortaleceram países emergentes. Os grandes líderes no mercado mundial de móveis hoje são: Estados Unidos, Itália, Alemanha e Japão, com um significativo aumento da participação de mercado da China, que até o ano de 2003 não aparecia no ranking global com um percentual significativo. O Brasil aparece em 12음 lugar, correspondendo a um market share de apenas 1\%. (RODRIGUES, 2006).

A figura 1 apresenta a distribuição do setor moveleiro no mundo. 


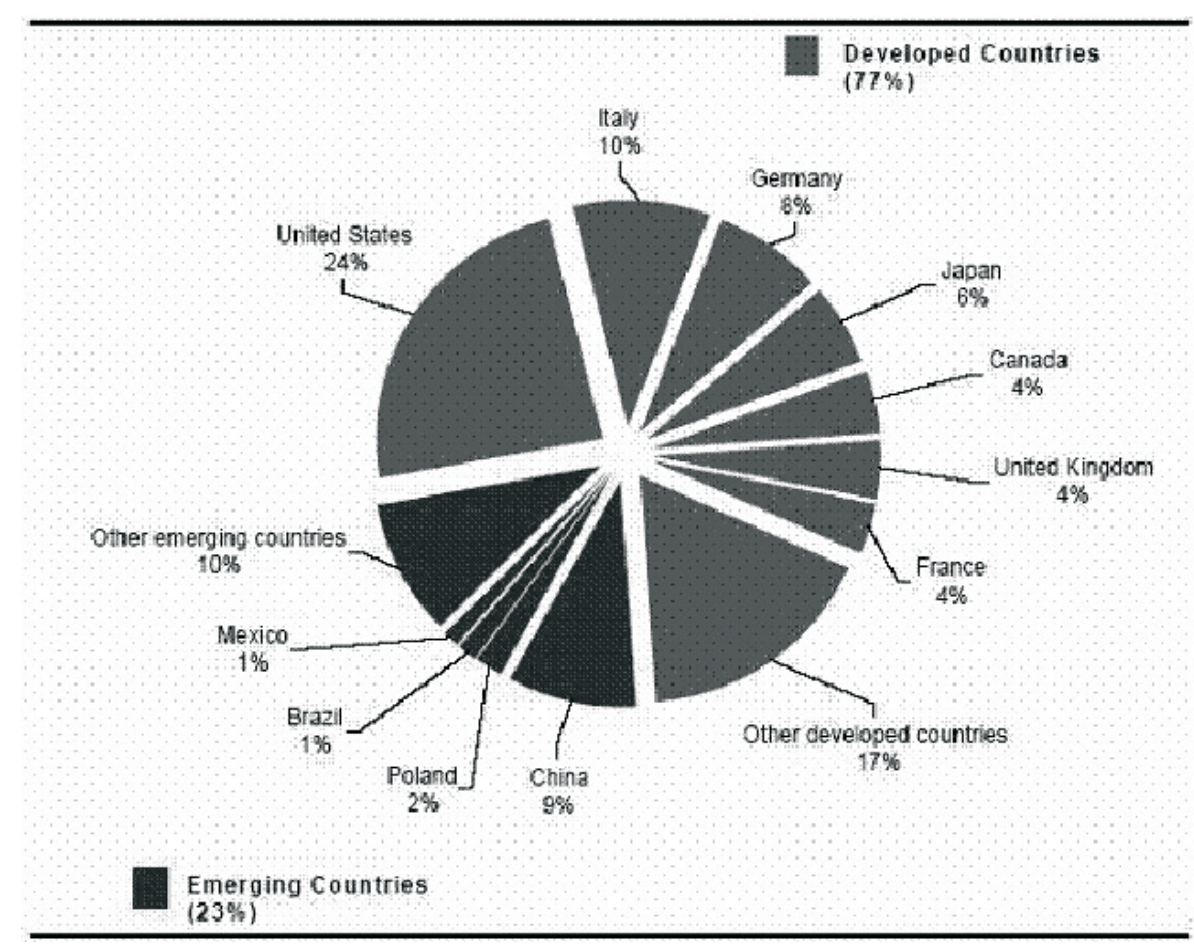

Figura 1 - Produção mundial de móveis Fonte: ABIMÓVEL (2005).

\subsubsection{Cenário nacional do setor moveleiro}

O setor moveleiro, no Brasil, é composto por empresas com estrutura de capital predominantemente nacional. Apenas nos últimos anos o capital estrangeiro tem adquirido alguns fabricantes nacionais no segmento de móveis de escritório. (CROCCO; HORACIO, 2001).

No que se refere à América do Sul, o Brasil representa cerca de $75 \%$ da produção de móveis e $67 \%$ do consumo. Apesar de possuir algumas vantagens competitivas significativas em relação aos principais países exportadores, como matéria-prima e mão de obra mais baratas, a indústria brasileira de móveis ocupa posição pouco relevante no comércio mundial (RODRIGUES, 2006).

As empresas moveleiras nacionais são, em sua grande maioria, empresas de porte pequeno e médio. A figura 2 apresenta as empresas de acordo com o número de funcionários, indicador esse que possibilita fazer inferências sobre o porte das empresas.

A produção de móveis no Brasil pode ser encontrada de maneira disseminada no território. Contudo, $90 \%$ da produção nacional e $70 \%$ da mão de obra do setor estão concentradas nas regiões Sudeste e Sul. O setor se apresenta distribuído em polos regionais, sendo os principais: Linhares, Votuporanga e Mirassol na região Sudeste; Bento Gonçalves, São Bento do Sul, Arapongas na região Sul e Ubá no Centro-Oeste. Segundo informações da RAIS (2005), existiam 16.112 empresas moveleiras no país.

O estado de São Paulo é responsável por cerca de $40 \%$ do faturamento do setor e responde por $80 \%$ da produção nacional de móveis para escritório. O estado de Santa Catarina é o maior exportador, responsável por quase metade das exportações brasileiras de móveis. Rio 


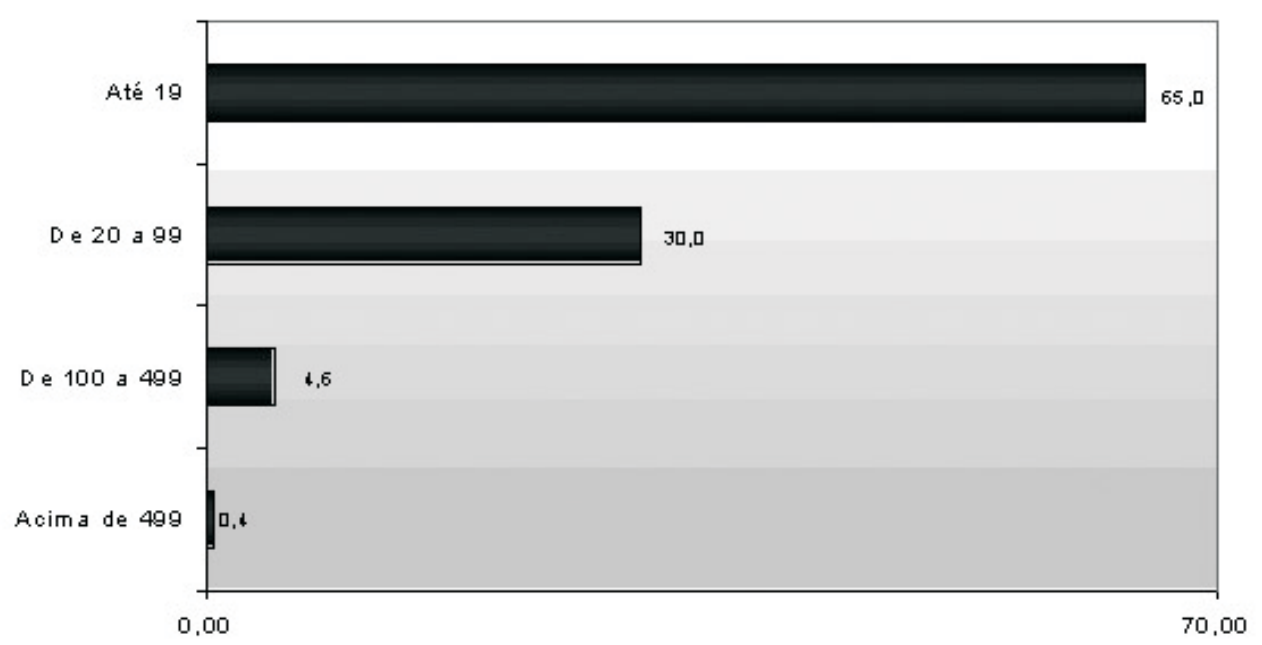

Figura 2 - As empresas em termos de número de funcionários Fonte: IEL/MG -GETEC (2003).

Grande do Sul e Santa Catarina têm níveis de qualidade e competitividade mais compatíveis com o mercado exterior. Os demais polos do país têm deficiências ligadas à baixa qualidade dos produtos, ao uso de equipamentos obsoletos, carência de mão de obra especializada e falta de cultura exportadora. Estes problemas não só dificultam maior inserção externa, como também indicam a existência de dificuldades para a produção nacional, devido à entrada de móveis importados no país em consequência da conclusão de acordos de livre comércio (RAIS, 2006; RODRIGUES, 2006).

As empresas produtoras de móveis surgiram na sua maioria a partir da década de 1950, quando se caracterizavam pela fabricação de móveis sob encomenda e tiveram sua forte expansão nos anos de 1980, com a modernização dos parques fabris e a expansão nas vendas. Durante a década de 1990, em vários países, a cadeia produtiva de madeira e móveis sofreu importantes transformações, com consequentes ganhos de produtividade a partir da introdução de equipamentos automatizados e a utilização de novas técnicas de gestão (RODRIGUES, 2006). As principais características da indústria nacional são o elevado número de micro e pequenas empresas, a grande absorção de mão de obra, o emprego de tecnologia média, a falta de design próprio e dificuldades para abertura de novos mercados.

\subsubsection{O APL moveleiro de Ubá}

Em Ubá, na década de 1960, um empreendedor iniciou suas atividades produzindo móveis em série. Ele fabricava seus produtos com os caixotes de madeira de um grande atacadista da cidade. Sua empresa cresceu e chegou a ter quase 1.000 funcionários. A partir daí seus próprios funcionários, empreendedores, foram, então, montando suas empresas. Não tiveram qualquer tipo de apoio do poder público. Como resultado, as empresas estão localizadas dentro da malha urbana, de modo que até hoje não há um distrito industrial em Ubá (INTERSIND, 2005). 
A indústria moveleira de Ubá e região reúne vários elementos capazes de caracterizála como um arranjo produtivo local de sucesso. Concentrando um número significativo de empresas com características similares, a economia de Ubá e seu entorno tem seus ciclos de desenvolvimento baseados no desempenho da indústria moveleira local.

O Polo Moveleiro de Ubá localiza-se na Zona da Mata Mineira e possui cerca de 310 empresas produtoras de móveis, localizadas na cidade de Ubá e redondezas (FERNANDES; OLIVEIRA JUNIOR, 2002; INTERSIND, 2005). Comparado com outros polos moveleiros nacionais, ocupa a 6 a posição em termos de número de estabelecimentos e a 4 à quanto à geração de empregos (IEL-MG/INTERSIND/SEBRAE-MG, 2003). A produção de móveis responde por cerca de $73 \%$ do emprego gerado no município e $61 \%$ do emprego disponível na indústria da região. A região apresentou um PIB da ordem de mais de $\mathrm{R} \$ 773$ milhões no ano de 2003, que é resultado direto do desempenho da indústria moveleira, já que, no caso do município de Ubá, por exemplo, mais de 56\% do número total de estabelecimentos estão atrelados à indústria de mobiliário (CROCCO; HORÁCIO, 2001; INTERSIND, 2004).

No que diz respeito à participação do poder público, observou-se que este tem agido apenas respondendo às fortes pressões dos empreendedores, a partir da percepção de certa vocação local, de modo que, para o surgimento do APL, essa participação pode ser considerada inexistente (SILVA, 2008).

Nesse trabalho, o empreendedor é visualizado de acordo com a perspectiva de Vale, Wilkinson e Amâncio (2008), como aquele que busca a melhor combinação possível de diferentes recursos produtivos, situados dentro ou fora da empresa, criando uma unidade produtiva em melhores condições de negociar no mercado, de modo a exercer um importante papel no surgimento e desenvolvimento dos APLs.

\subsection{Prospecção do polo em termos de cooperação: parceria entre os setores público e privado de outras naturezas}

A importância da cooperação entre os agentes locais é de extrema importância para o desenvolvimento dos APLs, pois esse fato tem sido evidenciado como a característica fundamental na sua cadeia produtiva. No entender de Casarotto e Pires (2001), a cooperação entre as empresas de porte menor é algo tão irreversível como a globalização, ou seja, talvez seja a maneira como as pequenas empresas possam assegurar sua sobrevivência e a sociedade garantir seu desenvolvimento equilibrado. Nesse aspecto, a cooperação se perfaz através de troca de informações entre empresas, intercâmbio de ideias, desenvolvimento de visão estratégica, análise conjunta dos problemas, solução em comum e definição das contribuições entre parceiros (ERBER, 2008).

Segundo a Redesist (2008), para que o desenvolvimento dos APLs tenha uma competitividade sustentável, deve ser inserido o potencial da cooperação na linha de frente dentre as suas conquistas. O aprendizado coletivo, conhecimento e capacidade inovativa seriam consequência do potencial da cooperação.

A cooperação em APLs pode ser percebida entre as empresas e também entre setores do Governo e as empresas, na forma de parcerias, fato que tende a proporcionar melhores condições ao desenvolvimento dos APLs.

De acordo com diagnóstico publicado pelo SEBRAE (2003), como forma de alavancar o APL moveleiro de Ubá, alguns agentes assinaram um termo de cooperação mútua, com o objetivo de promover o desenvolvimento conjunto de acordo com suas competências. São eles: Sindicato Intermunicipal das Indústrias de Marcenarias de Ubá (INTERSIND); Serviço de Apoio 
às Micro e Pequenas Empresas de Minas Gerais (SEBRAE); Itatiaia Móveis S/A; Renner Sayerlack S/A; Agência de Desenvolvimento de Ubá e Região (ADUBAR); Serviço Nacional de Aprendizado Industrial (SENAI); Prefeitura Municipal de Ubá; Associação Comercial Industrial de Ubá (ACIU); Movimento Empresarial Ltda.; Instituto Euvaldo Lodi (IEL); Universidade Federal de Juiz de Fora (UFJF) e Universidade Federal de Viçosa (UFV). Há também empresas que desenvolvem trabalhos em parceria com o polo, mas que ainda não assinaram o termo de cooperação mútua: Agência KyKo Garcia; Banco do Brasil S/A; Banco de Desenvolvimento de Minas Gerais; Caixa Econômica Federal; Instituto de Desenvolvimento Industrial de Minas Gerais; Programa Municipal de Defesa do Consumidor; Universidade Presidente Antônio Carlos (UNIPAC) e Associação dos Exportadores de Móveis de Ubá e Região (Movexport).

\section{Metodologia}

Esta pesquisa apresentou caráter exploratório e descritivo e abordagem predominantemente qualitativa, uma vez que não trouxe hipóteses testáveis estatisticamente. Como se pretende fazer uma descrição dos fenômenos e percepções dos atores envolvidos com as políticas públicas, a pesquisa qualitativa, segundo Godoy (1995, p. 62), proporciona uma compreensão ampla dos fenômenos, considerando que todos os dados da realidade são importantes e devem ser examinados. Utilizou-se do estudo de caso como forma de aprofundar o conhecimento sobre um caso específico. Yin (1994) destaca que o método do estudo de caso é indicado para a análise de fenômenos contemporâneos, especialmente quando o limite entre o fenômeno e o contexto não estão bem definidos.

A pesquisa foi realizada em duas etapas:

a) a primeira etapa consistiu em levantamento bibliográfico das informações sistematizadas sobre o APL em documentos e outras publicações;

b) na segunda etapa, foram realizadas entrevistas semiestruturadas, com agentes estratégicos do APL, a saber, representantes do Serviço de Brasileiro de Apoio às Micro e Pequenas Empresas (SEBRAE), Sindicato Intermunicipal das Indústrias de Marcenaria de Ubá (Intersind), Movimento Empresarial e Secretaria Municipal de Desenvolvimento, escolhidos de forma nãoaleatória para fornecer informações não disponíveis na literatura sobre o processo de desenvolvimento do polo e as políticas de incentivo. Para Vergara (2006), a entrevista é considerada um meio superior de obtenção de dados, devido ao caráter de profundidade que pode ser alcançado. Uma limitação do estudo de caso prevista por Yin (1994) é o fato de não se poder fazer generalizações.

\section{Resultados e discussões}

Percebeu-se a existência de poucas políticas públicas que contemplem o APL moveleiro de Ubá, com base nas entrevistas e em consultas bibliográficas.

No caso do APL moveleiro de Ubá, pôde-se verificar que as ações empreendedoras e o protagonismo local são diretrizes e pré-requisitos para a existência de políticas públicas federais. 
Não existiam coisas concretas. Em 2003, por iniciativa MDIC, surgiu a idéia de fazer um grupo-base que vai discutir o APL e fazer políticas para o APL. [Entrevista 2].

Toda a literatura e todo o nosso trabalho [GTP APL] é pautada na questão do protagonismo dos atores locais. Nosso trabalho é todo a partir do protagonismo local. [Entrevista 1].

Das políticas encontradas, nem todas atendem real e efetivamente às empresas integrantes do polo. Em 2003, com a institucionalização do APL e a criação do Grupo de Trabalho Permanente (GTP APL), um número maior de políticas públicas foi percebido, com formulações um pouco mais apropriadas ao atendimento das especificidades do polo. Exemplo é a atenção dada ao desenvolvimento das exportações, com projetos da Agência Brasileira de Promoção de Exportações (APEX), e um projeto de 2004, denominado "Minas Exporta com Excelência", que fez parte do planejamento plurianual, desenvolvido pelo Governo de Minas por meio da Secretaria de Estado e Desenvolvimento Econômico.

Pretendia-se gerar a cultura exportadora. Então foram realizados treinamentos em Ubá sobre como exportar. [Entrevista 2].

Tem subsídio! Existe o projeto o Brasilian Furniture da ABIMOVEL que representa uma parceria com a APEX para fomento da exportação. Feira de eventos, projeto exportador e participações em feiras internacionais. [Entrevista 3].

O projeto PEIEX é um exemplo claro de política pública! É uma plataforma do Governo Federal para fomento da exportação. Ocorre a capacitação das empresas através de cursos e treinamentos e consultoria individualizada nas empresas. [Entrevista 4].

De acordo com Silva (2008), a maior parte das políticas públicas destinou-se à promoção do comércio externo dos produtos do APL, enquanto quase nada foi identificado para a preparação de um clima de confiança que estimulasse o investimento (clima do ambiente econômico)

Conforme Intersind (2005), o polo moveleiro de Ubá começou, recentemente, a desenvolver projetos de compras conjuntas, algo que não ocorria por questões relativas à desconfiança por parte dos empresários. Para Albino e Souza (2008), em outros aspectos referentes à cooperação entre agentes, o APL ainda se mostra incipiente.

Dentre as ações estratégicas monitoradas pelo Acordo de Resultados consta a capacitação de colaboradores. O Ministério do Desenvolvimento da Indústria e Comércio (MDIC), por meio de convênio com o IEL/MG, capacitou um grupo de 20 empresas para exportar, além de reforçar o consórcio de exportação MOVEXPORT com 13 empresas do APL de Móveis de Ubá/MC (CERVIERI, 2005).

Segundo o representante do Intersind:

Há um esforço dos governos em desenvolver os APLs e a partir dos trabalhos realizados em Ubá, o APL está sendo beneficiado, como, por exemplo, na participação de editais da Finep, da Fapemig, e outros para aumentar a quantidade de produtos exportados [Entrevista 1].

O esforço conjunto para melhoria e capacitação da mão de obra pode ser percebido no seguinte depoimento:

Rev. Adm. UFSM, Santa Maria, v. 3, n. 2, p. 230-244, mai./ago. 2010 
Nós tivemos esse ano a implantação da UEMG pela Prefeitura... Ubá tem também um Centro Vocacional Tecnológico... foi feito um laboratório pra área de marcenaria... [Entrevista 4].

Outras ações foram desenvolvidas ou estão em fase de implantação, de acordo com os dados coletados nas entrevistas. O município tem uma proposta de investimento em infraestrutura que irá, por exemplo, ampliar o aeroporto municipal, para que tenha linhas diretas para Rio e São Paulo. Já a Prefeitura de Visconde do Rio Branco instalou um distrito industrial na cidade. O Governo de Minas está fomentando o plantio de eucalipto na região, uma parceria entre a UFV e demais parceiros. A UFV possui vários projetos encerrados e em andamento nas diversas áreas, como: ergonomia, design, tecnologia da madeira, teste de produtos acabados etc.

A evidência é dos primeiros sinais de investimento no APL. A figura 3 apresenta a forma e disposição dos agentes que trabalham para o desenvolvimento do APL.

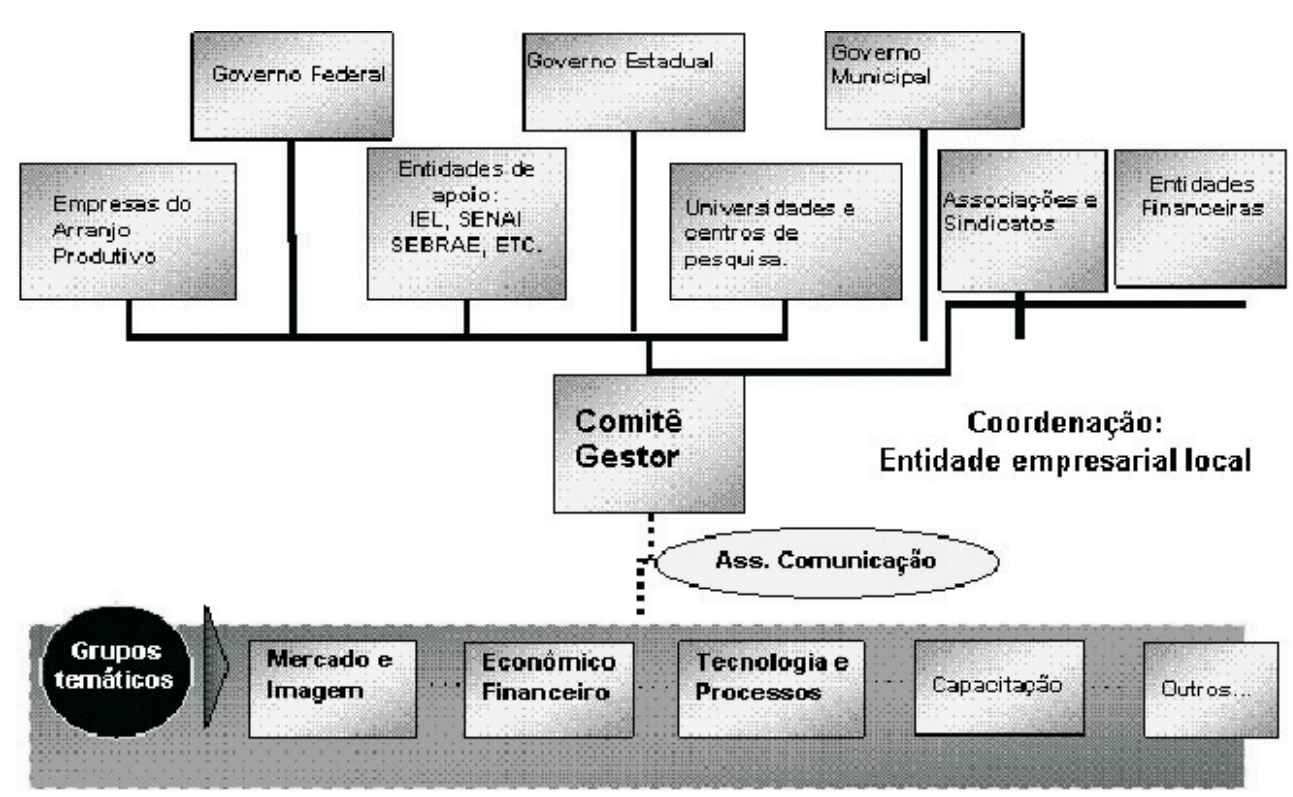

Figura 3 - Modelo de governança para APLs

Fonte: Gerência de Estudos e Projetos Tecnológicos/IEL-MG, 2003.

O modelo de governança apresentado indica um avanço para o desenvolvimento dos APLs, dado que, por meio dos grupos de trabalho, criaram-se ações e projetos que contemplam diferentes segmentos e demandas do APL.

Pode-se perceber que as ações estão distribuídas entre os grupos temáticos, de modo a equilibrar os resultados obtidos. Todas as ações são evidenciadas no Acordo de Resultados, instituído no Programa Choque de Gestão, que no caso dos APLs vem sendo é acompanhado e atualizado pelo Sebrae, de forma a garantir o cumprimento e verificação do andamento das mesmas (VILHENA et al., 2006).

Algumas ações sugeridas para o desenvolvimento do polo a serem executadas entre 2007 e 2009 são: plantio e manejo de floresta para o setor moveleiro, desenvolvimento de projetos de design, avaliação da qualidade dos produtos, promoção de campanhas relacionadas ao meio ambiente, estação de efluentes líquidos cooperada, capacitação de indústrias em ges- 
tão empresarial, capacitação de mão de obra profissionalizante, promoção da interação entre instituições de ensino e empresas, melhoria de infraestrutura do APL, criação e desenvolvimento da central de fretes, participação em feiras e eventos nacionais e internacionais, com atenção especial aos eventos locais Feira de Máquinas e Equipamentos (FEMAQ) e Feira de Móveis de Ubá e Região (FEMUR), entre outras ações. O trecho seguinte apresenta um sinal de investimento no sentido de promover o desenvolvimento sustentável do APL em termos de matériaprima, e percebe-se que atitudes como essas que partem do Governo são recentes:

\footnotetext{
Precisaria ter fomento e também ter o plantio... e aí já não se conseguia mais essa negociação com o governo do estado nem com o governo municipal... Exemplo é a planta da Minas Plac [fábrica de aglomerado] que era para ser instalada em Ubá, acabou sendo instalada em Uberaba, onde existem as políticas de plantio. [Entrevista 4].

Agora o Estado começou a colocar o abastecimento do setor moveleiro em relação ao plantio de eucalipto, sendo essa uma meta do governo. O Estado colocou isso como meta foi a partir desse ano! [Entrevista 3].
}

Ainda que políticas públicas tenham sido implementadas com o objetivo de promover o desenvolvimento dos APL, incluindo o caso de Ubá, de acordo com os resultados das pesquisas de Souza (2003) e de Albino e Souza (2008), as políticas de incentivo e programas de apoio ao desenvolvimento e à competitividade são distribuídas de forma genérica a regiões ou a setores, tratando os aglomerados e segmentos industriais de forma homogênea e integral, de modo que, muitas vezes, essas políticas não atendem a todos os componentes dos arranjos.

Como exemplo citado anteriormente, a distribuição e localização de novas unidades no entorno da malha urbana central do polo indica que fatores como a falta de infraestrutura podem estar comprometendo a expansão de algumas fábricas no local de origem de atuação, o que, conjugado com outros fatores, revelam que o APL em termos de infraestrutura apresenta condições insatisfatórias e a disposição fragmentada das empresas pode ser considerada um entrave para a integração e o fortalecimento das relações de cooperação e parcerias entre as mesmas (ALBINO e SOUZA, 2008).

Como o APL moveleiro de Ubá agora apresenta de forma mais evidente o apoio do Governo Federal, algumas reflexões se fazem oportunas. Problemas como os expostos acima, entre outros que se fazem presentes, somados aos aspectos diversos encontrados nas empresas do APL, suscitam preocupações no sentido de que as políticas públicas necessitam apresentar formas diferentes de atuação, de modo a reconhecer características mais frequentes em determinados grupos, para, a partir desse ponto, orientar mais as ações.

\section{Conclusões e sugestões para futuras pesquisas}

Dado que é perceptível o papel importante do APL moveleiro de Ubá para a geração de empregos e desenvolvimento local e regional, podem-se tirar as seguintes conclusões sobre o APL:

- o APL moveleiro de Ubá surgiu e se desenvolveu praticamente sem o suporte de políticas públicas que deveriam agir como fertilizadoras do ambiente de negócios;

- no caso específico de Ubá, o comportamento empreendedor exerceu influência determinante para criação e desenvolvimento do arranjo; 
- a partir do desenvolvimento do APL e, principalmente após sua institucionalização, é que se passou a formular políticas um pouco mais apropriadas para atender às demandas do arranjo, como é o caso das ações estabelecidas no Acordo de Resultados. Os acordos já representam um passo mais amplo no sentido de incorporar novos recursos ao desenvolvimento do polo e, consequentemente, da região. O trecho da entrevista que segue evidencia essa participação do poder público:

Até a institucionalização do APL o poder público não direcionava esforços para o desenvolvimento do pólo... era parceiro mas não comparecia às reuniões... Em 2005 o Governo Federal já começou a entender esta questão de Arranjos Produtivos Locais e através do Ministério do Desenvolvimento Indústria e Comércio criou-se o Grupo de Trabalho Permanente, em que o Governo Federal priorizou onze Arranjos Produtivos no Brasil, incluindo do de Ubá [Entrevista 2].

De acordo com os dados coletados, pode-se concluir também que, no caso do APL de Ubá, as políticas públicas de incentivo tiveram caráter apenas financiador, principalmente em termos de disponibilização de verbas para treinamentos para os participantes.

Percebeu-se que, no APL, apresentam-se assimetrias no que se refere ao estágio de desenvolvimento e às características diferentes das empresas, de modo que existe a necessidade da revisão e reorientação das políticas públicas no sentido de reconhecer e atender aos tipos diversos presentes no polo, bem como ter mais agilidade no atendimento das demandas. Ações genéricas podem não captar as reais necessidades das empresas por causa dessa natureza diversa.

Estudos sobre a diversidade das empresas serão importantes no sentido de apresentarem características das empresas, de modo que poderá ocorrer uma melhor orientação das políticas, tornando-as mais abrangentes e eficazes.

\section{Referências}

ABIMÓVEL. Panorama do setor moveleiro no Brasil. São Paulo: 2005. Disponível em: >http:// www.abimovel.org.br/>. Acesso em: 19 abr. 2008.

ALBINO, A. A., SOUZA, S. D. C. Aplicação do modelo diamante de Porter e análise dos determinantes da competitividade para o apl moveleiro de UBÁ. In: SIMPÓSIO DE ENGENHARIA DE PRODUÇÃO, 15., 10-12 nov. 2008, Bauru. Anais... Bauru: UNESP, 2008. (artigo aprovado).

AWUAH, G. B. A firm's competence development throgh its network of exchange relationships. Journal of Business e Industrial Marketing, v. 16, n. 7, p. 574-599, 2001.
BRITO, J. Características dos clusters na economia brasileira. Rio de Janeiro: IE/UFRJ, 2000.

BRITO, J.; ALBAGLI, S. Glossário de arranjos e sistemas produtivos e inovativos locais. Arranjos e Sistemas Produtivos Locais e as Novas Políticas de Desenvolvimento Industrial e Tecnológico, Instituto de Economia da Universidade Federal do Rio de Janeiro - IE/UFRJ, 2001. Disponível em: <http:// www.ie.ufrj.br/redesist > . Acesso em: 05 maio 2008.

CASAROTTO, F. N.; PIRES, L. H. Redes de pequenas e médias empresas e desenvolvimento local. São Paulo: Atlas, 2001.

CERVIERI, C. M. Secretaria Técnica do GTP APL. Resultados do GTP APL. $2^{\text {a }}$ Conferência Brasileira sobre Arranjos Produtivos Locais. Rio de Janeiro, 12 a 14 de setembro de 2005. 
CROCCO, M.; HORÁCIO, F. Industrialização descentralizada: sistemas industriais locais o arranjo produtivo moveleiro de Ubá. Arranjos e Sistemas Produtivos Locais e as Novas Políticas de Desenvolvimento Industrial e Tecnológico, Instituto de Economia da Universidade Federal do Rio de Janeiro - IE/UFRJ, 2001. Disponível em: <http:// www.ie.ufrj.br/redesist>. Acesso em: 05 maio 2008.

DELGADO, G. C. O papel das políticas públicas. 16. ed. Desafios do desenvolvimento, IPEA/PENUD, nov. 2005. Disponível em: <http:// www.desafios.ipea.gov.br/edicoes/16/artigo133081asp>. Acesso em: 25 jul. 2008.

DINIZ, C. C. Desenvolvimento poligonal no Brasil: nem desconcentração nem contínua polarização. Revista Nova Economia, Belo Horizonte, v. 3, n. 1, 1993. p. 35-64.

DINIZ, C. C. Global-Local: interdependências e desigualdade ou notas para uma política tecnológica e industrial regionalizada no Brasil. 2000. 29p. Nota Técnica -Arranjos e Sistemas Produtivos Locais e as Novas Políticas de Desenvolvimento Industrial e Tecnológico, IE/UFRJ, Rio de Janeiro, 2000.

ERBER, F. S. Eficiência coletiva em arranjos produtivos locais industriais: comentando o conceito. Nova economia. [online]. v.18, n.1, p. 11-31, 2008,

FERNANDES, C.L.L.; OLIVEIRA JUNIOR, R. H. Cluster no setor moveleiro: um estudo das potencialidades da região de Ubá (MG). In: SEMINÁRIO SOBRE A ECONOMIA MINEIRA DIAMANTINA, 10., jun. 2002. Disponível em: <http:cedeplar.ufmg.br/diamantina2002/textos/ D31.pdf> Acesso em: 18 jun. 2008.

GODOY, A. S. Introdução à pesquisa qualitativa e suas possibilidades. Revista de Administração de Empresas, São Paulo, v. 35, n. 2, p. 57-63, 1995.

GRASSI, A. Cidades médias têm maior crescimento econômico do país. Jornal A Folha. Disponível em: <http://www1.folha.uol.com.br/folha/treinamento/ novoemfolha45/ ult10096u419369.shtml > . Acesso em: 04 abr. 2009.

IEL-MG/INTERSIND/SEBRAE-MG Diagnóstico do polo moveleiro de Ubá e região. Belo Horizonte, 2003.
INTERSIND. Femur 2004. Disponível em: < http:// www.intersind.com.br/femur $>$. Acesso em: 11 abr. 2008.

INTERSIND. - 15 anos: publicação comemorativa dos quinze anos do Intersind. Minas Gerais: Suprema, 2005.

LASTRES, H.M.M; CASSIOLATO, J.E.; MACIEL, M.L. Pequena empresa: cooperação e desenvolvimento local. Rio de Janeiro: Relume Dumará, 2003.

LASTRES, H.M.M.; CASSIOLATO, J.E. Glossário de arranjos e sistemas produtivos e inovativos locais: redes de pesquisas em sistemas produtivos e inovativos locais - Redesist. Instituto de Economia da Universidade Federal do Rio de Janeiro - IE/UFRJ, 2001. Disponível em: <http://redesist.ie.ufrj.br>. Acesso em: 15 abr. 2008.

PEREIRA, J. P. C. N.; CARVALHO, M. M. Cooperação e localidade: uma análise no contexto do agronegócio de flores. Revista Produção, v. 18, n. 1, p. 185-209, jan./abr. 2008.

PORTER, M. E. A vantagem competitiva das nações.Rio de Janeiro: Campus, 1990.

PORTER, M.E. Competição on competition: estratégias competitivas essenciais. Rio de Janeiro: Campus, 1999.

PRAHALAD, C. K.; HAMMEL, G. The core competence of the corporation. Havard Business Review, v. 68, n. 3, p. 79-91, maio/jun. 1990.

RAIS. Relação Anual de Informações Sociais. 2005. Disponível em: <http://www.rais.gov.br/> . Acesso em: 25 jul. 2008.

. 2006. Disponível em: <http:// www.rais.gov.br/>. Acesso em: 14 abr. 2008.

REDESIST. Rede de Sistemas Produtivos e Inovativos Locais - Instituto de Economia da Universidade Federal do Rio de Janeiro. Disponível em: <http:// www.redesist.ie.ufrj.br > Acesso em: 10 mar. 2008.

RODRIGUES, T. L Um estudo sobre cooperação em arranjos produtivos locais: Serra Gaúcha e Ubá. São Leopoldo: UNISINOS, 2006. 
SEBRAE. Arranjos produtivos locais. 2004. Disponível em: <http://www.sebrae.com.br/br/cooperecrescer/ arranjosprodutivoslocais.asp $>$. Acesso em: 25 abr. 2008.

SILVA, A. R. O papel das políticas públicas no desenvolvimento sustentável do arranjo produtivo moveleiro de Ubá-MG. 2008, 162f. Dissertação (Mestrado em Administração)-Universidade Federal de Viçosa, Viçosa, 2008.

SOUZA, S. D. C. Uma abordagem evolucionária da dinâmica competitiva em arranjos produtivos locais. 2003, 353 f.Tese (Doutorado em Engenharia de Produção)-Universidade Estadual Norte Fluminense, Campos dos Goytacazes, 2003.

VALE, G. M. V; WILKINSON, J.; AMÂNCIO, R. Empreendedorismo, inovação e redes: uma nova abordagem. RAE Eletrônica, v. 7, p. 1-17, 2008.

VERGARA, S. C. Métodos de pesquisa em administração. São Paulo: Atlas, 2006.

VILHENA, R. et al. (Org.). O choque de gestão em Minas Gerais. Belo Horizonte: Ed. da UFMG, 2006.

YIN, R. K. Case study research: design and methods. London: Sage, 1994.

SCHMITZ, H. Colletive efficiency: growth pach for small scale industry. The Journal of Development Studies, v. 31, n. 4, p. 529-566, 1995. 